\title{
Transferring Innovative Erosion and Sediment Control Research Results into Industry Practice
}

\author{
Michael A. Perez ${ }^{1, *} \mathbb{\infty}$, Wesley C. Zech ${ }^{2} \mathbb{D}$, Wesley N. Donald ${ }^{1}$, Rod Turochy ${ }^{1}$ and \\ Barry G. Fagan ${ }^{3}$ \\ 1 Department of Civil Engineering, Auburn University, Auburn, AL 36849, USA; \\ donalwn@auburn.edu (W.N.D.); rodturochy@auburn.edu (R.T.) \\ 2 Department of Civil Engineering and Construction Management, The University of Alabama Birmingham, \\ Birmingham, AL 35294, USA; zechwes@uab.edu \\ 3 Volkert, Inc., Montgomery, AL 36117, USA; barry.fagan@volkert.com \\ * Correspondence: map0032@auburn.edu; Tel.: +1-334-844-6267
}

Received: 19 September 2019; Accepted: 29 November 2019; Published: 3 December 2019

check for

\begin{abstract}
Erosion and sediment controls (ESCs) are essential components of construction projects in minimizing downstream environmental impact. Since 2014, the Auburn University-Erosion and Sediment Control Testing Facility has hosted training events focused on disseminating results of innovative construction stormwater research to practitioners to help close the gap between research results and implementation. The purpose of training is to provide participants with the opportunity to learn about various practices used in construction settings to manage stormwater runoff. The result is increased knowledge of stormwater management which will translate into better protection of water resources. The facility has the unique capability of producing flows to simulate runoff typical of construction activities using research apparatuses, allowing attendees to understand how devices react when subject to field-like runoff conditions. The facility has provided training through a total of nine offerings with 764 participants. The purpose of this manuscript is to evaluate the effectiveness of the delivery style of these courses in providing technology transfer to industry professionals. In distributed surveys, attendees were asked to rank their level of knowledge prior to and after attending the training programs in ten specific focus areas covered during training. Overall, knowledge measurements indicated that technical knowledge level was improved across all measured areas with an average increase in perceived knowledge of $82 \%$ for a 1.5-day hands-on installer training event and 36\% for a 1-day field day.
\end{abstract}

Keywords: erosion and sediment control; stormwater; large-scale testing; technology transfer; construction

\section{Introduction}

Stormwater discharges from construction activities can cause significant physical, chemical, and biological water quality impacts and impairments. As stormwater runoff flows over unprotected areas on construction sites, it can suspend and transport pollutants (e.g., sediment, debris, and chemicals) to nearby receiving waters [1,2]. Suspended sediment degrades water quality by blocking sunlight, decreasing aquatic plant growth, reducing visibility, and destroying bottom-dwelling species' habitat. Furthermore, sediment has the potential to reduce stormwater conveyance capacities, leading to increased stream scour and flooding potential [3]. The inherent nature of construction activities produces high potential for stormwater pollution through erosion and sediment discharge from the removal of vegetation from large land areas. Therefore, it is important to ensure the in-field 
performance of various erosion and sediment control (ESC) practices, products, and installations as mitigation measures for lessening the impact associated with construction stormwater discharges.

The urgency for soil conservation was sparked by the Dust Bowl of the 1930's, which resulted in the formation of the Soil Erosion Service in 1933 by President Franklin D. Roosevelt [4]. The Clean Water Act of 1972 established the National Pollutant Discharge Elimination System (NPDES), which triggered federal, state, and local stormwater regulations [5]. The NPDES regulations require construction site operators to obtain coverage under the Construction General Permit (CGP) if they are engaged in clearing, grading, and excavating activities that disturb one or more acres. The United States Environmental Protection Agency (USEPA) and state environmental agencies oversee these CGPs. Construction site operators are required to develop a stormwater pollution prevention plan (SWPPP), implement erosion, sediment, and pollution prevention control measures, and regularly inspect and maintain these practices as needed [6].

Since the enactment of construction stormwater regulations, several organizations and associations have formed to provide related research, testing, and continuing educational resources for the construction industry. One such entity, the International Erosion Control Association (IECA), was formed in 1972 with the intent to collect and disseminate information, encourage industry research, promote professional skills and education, and develop industry standards. Today, IECA hosts a national conference, several regional conferences, field days, and webinars. The IECA University Partners Program is an initiative focused on involving research institutions and young professionals within the industry. ESC certification programs, such as those offered by EnviroCert International, Inc. serve to recognize professionals who have demonstrated qualifications based on education, experience, and examinations. ASTM International and the American Association of State Highway and Transportation Officials (AASHTO) maintains standard test methods and procedures for evaluating the performance of ESC technologies for the industry.

Traditionally, ESC practices are designed based on practical experience and "rules of thumb", rather than research results. These "rules of thumb" have governed the selection and installation of many ESC practices currently employed in the industry. Practitioners refer to design recommendations or requirements from various state ESC manuals, such as the Alabama Handbook for Erosion Control, Sediment Control and Stormwater Management on Construction Sites and Urban Areas published by the Alabama Soil and Water Conservation Committee (AL-SWCC) [7]. Through the results of recent research efforts, ESC designs are transitioning towards hydraulic- and hydrologic-based designs to better cater to site parameters and improve the performance of practices [8-15].

While educational and research resources for ESC designs have increased in availability, a need still exists to fill the gaps between the knowledge base developed through research and the needs of practitioners. Technology Transfer programs provide the platform to disseminate knowledge, practice, and techniques to industry professionals [16].

\section{ESC Training in Alabama, USA}

Several state environmental protection agencies maintain construction stormwater education and certification programs. The Alabama Department of Environmental Management (ADEM) requires Qualified Credential Inspector (QCI) certification for stormwater inspectors working in the state. Currently, an eight-hour QCI course is offered by two organizations: Thompson Engineering, and the Home Builders Association of Alabama. Inspectors are required annually to maintain their QCI status by completing a four-hour yearly refresher course.

In addition to formal QCI instruction, an annual seminar is hosted by the Alabama ESC Partnership, which offers the "Clear Water Alabama Seminar and Field Day". This seminar provides an overview of changes in state regulatory requirements, new innovative practices and products, and research updates. The two-day event includes eight hours of presentations from industry experts, followed by an eight-hour field day consisting of site visits to various local construction sites to observe field installations and demonstrations. 
The Alabama Department of Transportation (ALDOT) is one of the largest facilitators of construction activities in the State of Alabama. As such, ALDOT not only has regulatory requirements and commitments but also carries an obligation to utilize practices that reflect the state-of-the-practice for effective management of construction stormwater. ALDOT construction runoff is regulated by a statewide NPDES general permit for construction discharge, and is regulated in urban areas by an ALDOT individual permit for Municipal Separate Storm Sewer System (MS4) discharges. Both regulatory permits require a measure of training and public education. However, ALDOT chooses to exceed these minimum requirements by investing heavily in internal and external learning through its funding and efforts in training, research, and other contributions to the broader construction stormwater knowledge base. While these programs are effective in providing regulatory and design information, a need for hands-on training exists. Hands-on training provides the means to disseminate practical field applications of ESC practices and improvements effectively to the industry (i.e., regulators, designers, inspectors, and installers) in an effort to improve the state-of-the-practice.

\section{AU-ESCTF Overview}

Construction stormwater pollution is a global problem; however, the Southeastern United States is especially vulnerable due to its heavy rainfall and highly erodible colloidal soils [17]. The climate in Alabama is classified as humid subtropical, with the state's average annual temperature at $64^{\circ} \mathrm{F}\left(18^{\circ} \mathrm{C}\right)$. The state borders the Gulf of Mexico is regularly subjected to tropical weather, with thunderstorms occurring year-round. Alabama's annual average rainfall depth is 62 in. $(132 \mathrm{~cm})$ [18]. The Auburn University-Erosion and Sediment Control Testing Facility (AU-ESCTF) was designed and constructed in 2009 as part of a research collaboration with ALDOT. The facility is located at the National Center for Asphalt Technology (NCAT) Pavement Test Track outside of Opelika, AL. The facility has the capability of assisting ALDOT, other state highway agencies, and municipalities with research, product evaluation, and training associated with ESC practices commonly used in construction. The AU-ESCTF operates on 1 ha $(2.5 \mathrm{ac})$ dedicated to the large-scale testing of ditch check, inlet protection practices, sediment basins, and sediment barriers. Figure 1 is an aerial photo of the AU-ESCTF illustrating the variety of demonstration stations during field days and testing apparatuses used when performing large-scale, channelized flow testing of ESC practices.

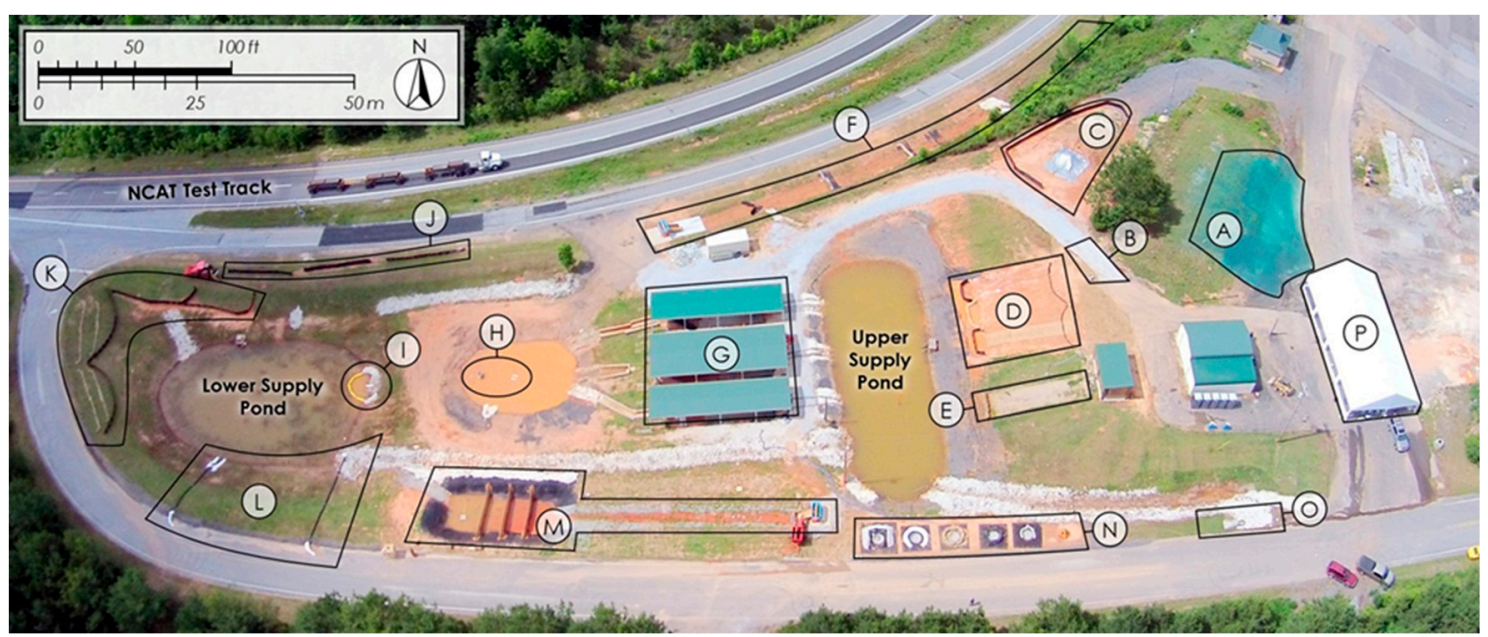

Figure 1. Aerial photo of the AU-ESCTF and training stations. Note: descriptions of stations A through $\mathrm{P}$ are provided below.

The mission of the AU-ESCTF focuses on three primary components: (1) research and development (R\&D), (2) product evaluation, and (3) training. R\&D consists of providing a scientific understanding of ESC practices used in construction to minimize impacts to the surrounding environment through performance-based, large-scale testing. The purpose of R\&D is to improve the effectiveness of current 
ESCs typically implemented in the field. Product evaluation provides independent, third-party, standardized testing of manufactured ESC practices seeking ALDOT approval to be included on their list of qualified materials, sources, and devices requiring special acceptance. Overall product performance is compared against conventional practices to evaluate whether a product provides a substantial improvement in either preventing erosion or promoting sedimentation on-site. The focus of training is on using knowledge learned through $R \& D$ and product evaluation testing, and transferring that knowledge to designers, contractor personnel, inspectors, and regulators to highlight improved ways of installing, maintaining, and inspecting various ESC practices on-site.

The AU-ESCTF has been engaged in ESC research activities since the facility's establishment. Through several ALDOT-funded research projects, the facility has provided improvements in the design and installation of ditch check, inlet protection, and sediment basin practices. Many of the research results from these studies have been adopted and implemented by ALDOT in their standard drawings, and by the AL-SWCC in the state ESC manual [7].

\section{Training Activities}

The primary goal of training workshops are to provide industry participants exposure to innovative research being performed on commonly employed ESC practices in both horizontal and vertical construction. Studies of best practices on implementation of research results have noted that no single type of activity is the best solution for accelerating the use of research results or innovations [16,19]. Therefore, a range of methods of technology transfer may facilitate the adoption of innovative problem-solving strategies into practice. The series of continuing education events held by AU-ESCTF and the Alabama Transportation Assistance Program (ATAP) include classroom seminar-style training, outdoor demonstrations of ESC practices, and hands-on opportunities for workshop participants to install practices.

The AU-ESCTF field days are intended to be innovation adoption processes, meaning the technology has been proven to be feasible, is available, and ready for implementation. Demonstrations show course participants the difference between traditional versus innovative installation techniques and the enhanced performance that is obtained by modifying the standard installation. Demonstrations have been identified to be a successful strategy for facilitating technology transfer, as they display the merits of the improved ESC practices [16].

By sharing knowledge gained through research, industry participants are better prepared to achieve environmental compliance. In addition, participants gain the needed knowledge in governing compliance regulations, leadership tactics, and hands-on design and implementation tools to provide efficient, effective, and improved ESC practices.

\section{Demonstration Stations}

During the field days, various ESC practices are installed at the AU-ESCTF in several locations (or stations) to facilitate the instruction and demonstration activities. The locations of individual stations at the facility are shown in Figure 1. A description of each station is provided below.

Station A: Hydroseeding. An area of exposed soil is used to provide demonstrations of a typical hydroseeding operation. Discussion on the type of seeding, germination, mulch, application rates, and application techniques are provided during events. Figure $2 \mathrm{a}$ shows a course participant applying hydromulch.

Station B: Construction Exit Pad and Housekeeping. This station, illustrated in Figure 2b, demonstrates a typical construction exit pad and an explanation of its construction specifications and function in removing soil from vehicle tires are discussed. This station also includes the demonstration of manufactured products equivalent to a typical construction exit pad. 


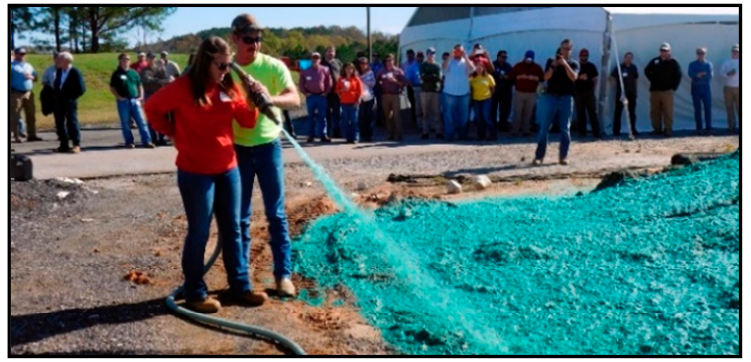

(a)

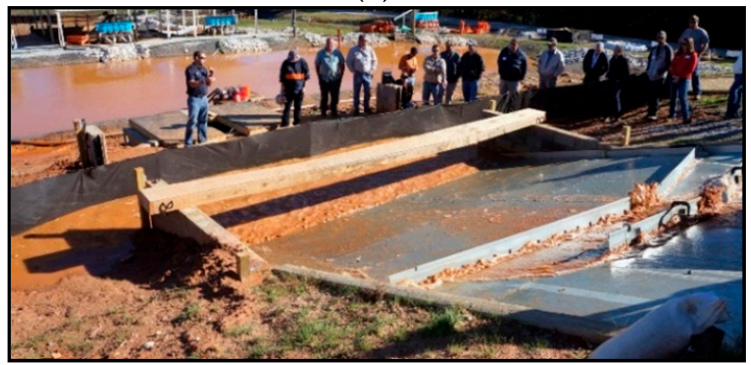

(c)

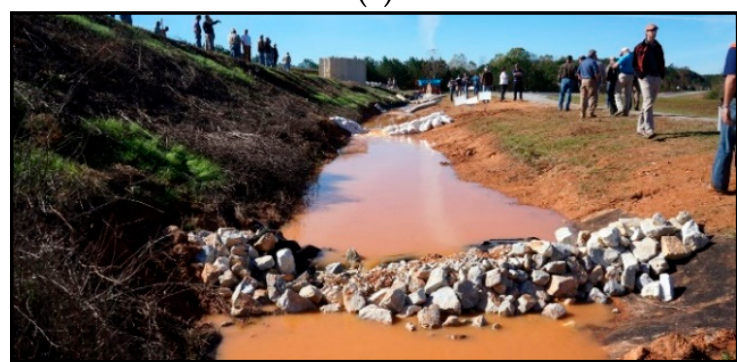

(e)

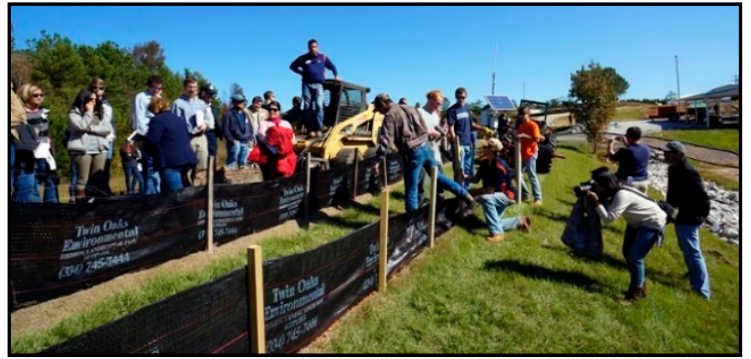

(g)

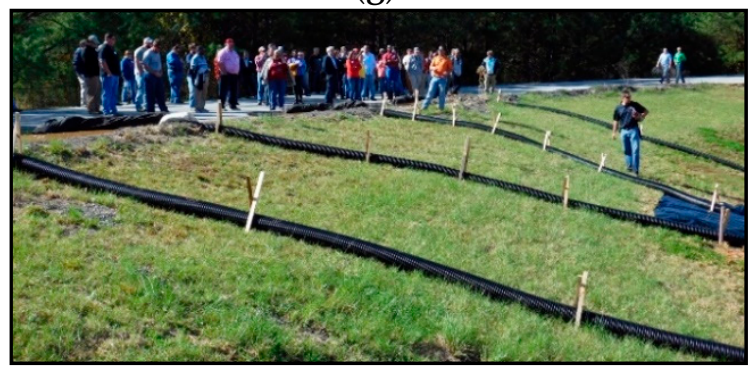

(i)

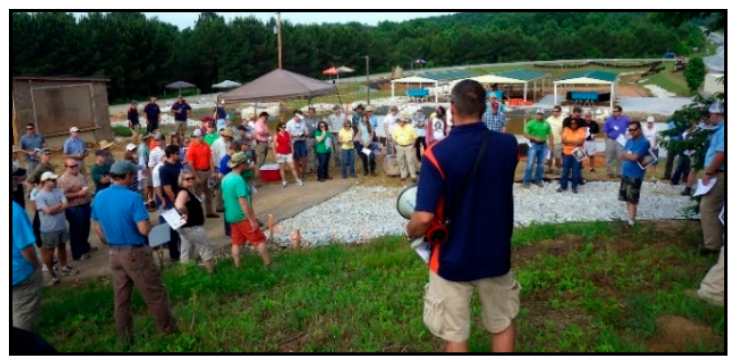

(b)

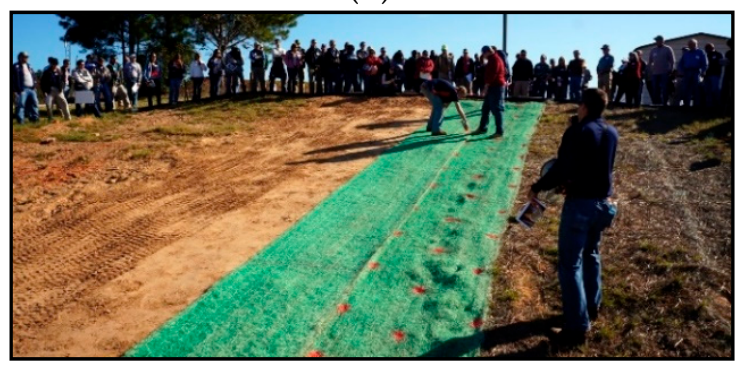

(d)

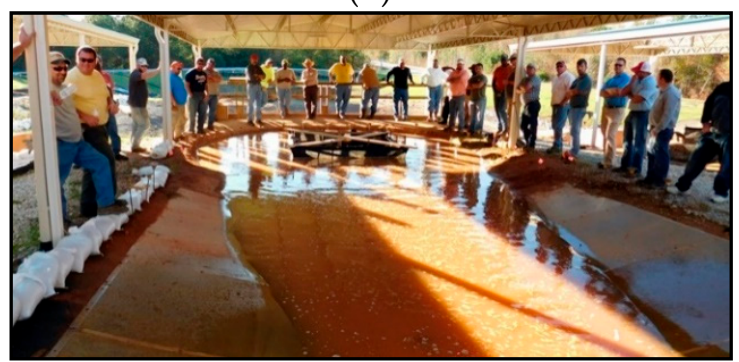

(f)

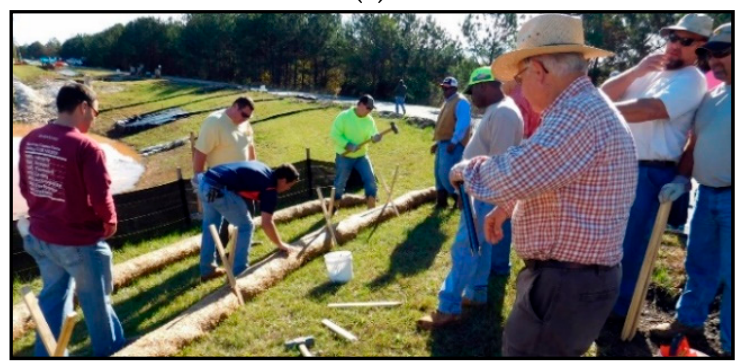

(h)

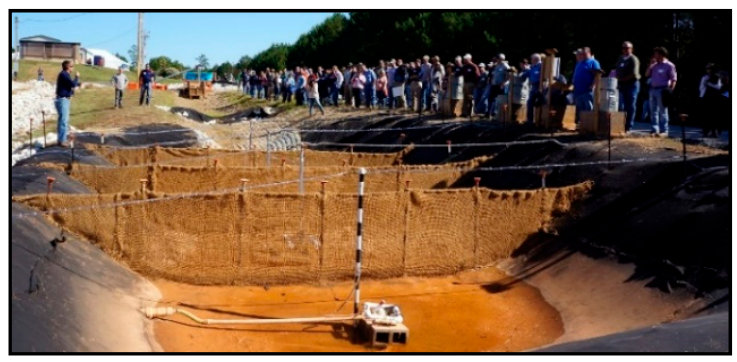

(j)

Figure 2. Demonstration stations at the AU-ESCTF: (a) Station A: Hydroseeding, (b) Station B: Construction Exit Pad, (c) Station D: Sediment Barriers, (d) Station E: Erosion Control Blankets, (e) Station F: Ditch Check Practices, (f) Station G: Channelized Flow Demonstration, (g) Station J: Silt Fence Installation, (h) Station K: Slope Interrupters, (i) Station L: Slope Drains, (j) Station M: Sediment Basin. 
Station C: Stockpile Management. The stockpile management station, allows for the demonstration of various techniques in providing cover and protection to soil stockpiles to prevent erosion, sediment transport, and creating a source of sediment discharge.

Station D: Sediment Barriers. Through an ongoing sediment barrier research project, this station provides the ability to demonstrate the sediment retention capabilities of various practices and products used as perimeter controls. A sediment barrier is installed prior to the field day and a demonstration is performed (Figure 2c) to exhibit flow impounding behind the practice.

Station E: Erosion Control Blankets. A bare slope is prepared prior to the field day to provide an erosion control blanket (ECB) demonstration. A description of the ECB's purpose and practice in protecting earthen slopes from rainfall-induced impact and encouraging vegetative establishment is given. The station includes a demonstration of proper installation techniques including ground preparation, seed and fertilizer spreading, trenching of the ECB at the top of the slope, unrolling of blanket, overlapping requirements, and stapling patterns to secure blanket to ground. A demonstration is typically performed using simulated sheet flow to compare erosivity of protected ground to a bare slope. Figure $2 \mathrm{~d}$ shows the installation of an ECB during a demonstration.

Station F: Ditch Check Practices. A description of ditch check practices, purpose, and proper installation techniques for reducing runoff velocity and erosive potential of channelized flows is provided using a $350 \mathrm{ft}(107 \mathrm{~m})$ channel. Up to eight ditch check practices are installed in the channel. Vendor participants are invited to install products the day prior to the field day. Channelized flows are simulated in the channel to provide participants with demonstrations on impoundment capabilities and common failure modes of the installed practices and products. Featured installations follow testing results published by AU-ESCTF researchers [20-22]. Figure 2e shows the ditch check channel during flow simulation.

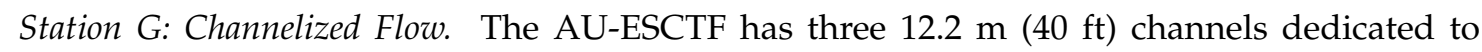
channelized flow testing of ditch check and inlet protection practices. These channels are used for research and product evaluation. During field days, practices are installed within channels to demonstrate the research apparatus and the performance of devices under simulated, real-world, flow conditions. Figure $2 \mathrm{f}$ shows an inlet protection practice subjected to flow in one of the AU-ESCTF research channels.

Station H: Floating Surface Skimmer. The facility has two surface floating skimmers, one installed in the facility's sediment basin and the other in the research sediment basin. These skimmers are used during the field day to demonstrate proper installation, maintenance, and function of the dewatering practices in basins.

Station I: Floating Turbidity Barrier. A floating turbidity barrier installed in the lower retention pond serves as a means to show the practice's purpose in limiting the spread of pollutants to a protected area within a water body. The proper installation technique and different barrier types are discussed.

Station J: Silt Fence Installation. Various silt fence types and installation techniques are shown at the silt fence installation station. Participants are educated on differences between woven and non-woven silt fence geotextile, as well as the different approved configurations for ALDOT and AL-SWCC specifications. Fences are installed during the field day to emphasize proper trenching, backfill, and post-spacing requirements. In addition to the traditional manual installation, a tractor implement is used to demonstrate the installation of wire-backed silt fence using a slicing technique. Figure $2 \mathrm{~g}$ shows the silt fence installation demonstration station.

Station K: Perimeter Control Techniques and Slope Interrupters. Two silt fence installation configurations are showcased in this station. Participants are shown how to properly install a "smile" configuration and "j-hooks" commonly used in areas with longitudinal slopes. This area is also used to install and describe slope interrupters, which are shown in Figure 2h.

Station L: Slope Drains, Outlet Control, and Level Spreader. At this station, the purpose and installation techniques for slope drains are discussed. Participants are shown how to properly funnel stormwater into slope drains as well as proper drain installation and anchoring techniques. The difference between 
single- and double-wall drains is explained as well as flocculent introduction techniques at the drain inlet. Energy-dissipation measures, such as upward-turned drains, a rip-rap outlet, and a sandbag spillway are demonstrated at the drain outlet with simulated flows. A level spreader is also installed at one of the drain outlets to demonstrate the practice's purpose in detaining stormwater and discharging flow in sheet-flow conditions. Figure $2 \mathrm{i}$ provides an illustration of this station.

Station M: Sediment Basin. The AU-ESCTF has a 17 by $8.5 \mathrm{~m}$ (56 by $28 \mathrm{ft}$ ) sediment basin dedicated to large-scale research efforts. The basin was originally used as part of a research project focused on improving the standard configuration through the use of high-rate lamella settlers [11,12]. The basin is used during field days to demonstrate how the sediment control feature functions on a construction site. Flows are simulated through the practice that allows participants to observe how the features within the basin function to remove suspended particles. Common installation errors, design recommendations, and current research findings are shared. The sediment basin station is shown in Figure $2 \mathrm{j}$.

Station N: Inlet Protection Practices. Six concrete riser structures are dedicated to provide mock storm drain inlets. Inlet protection practices are installed around these devices to showcase improved practices that have emanated from an inlet protection research study performed at the AU-ESCTF [10,13]. In addition to the non-proprietary practices, vendors are allowed to place their products in this area to showcase how they are installed in the field. Figure 3 shows the inlet protection practice installation area.

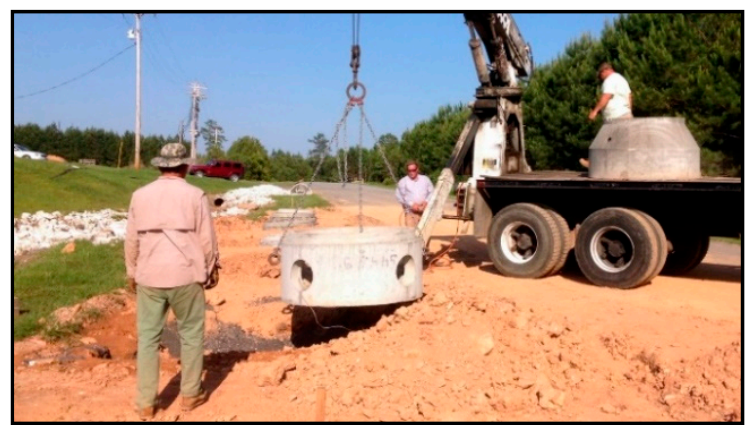

(a)

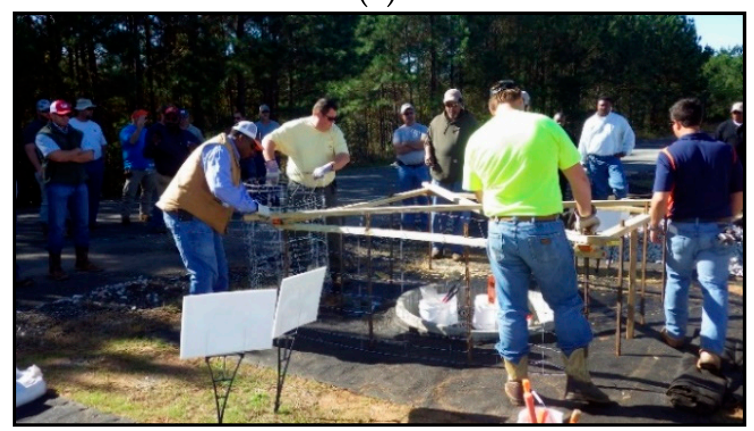

(c)

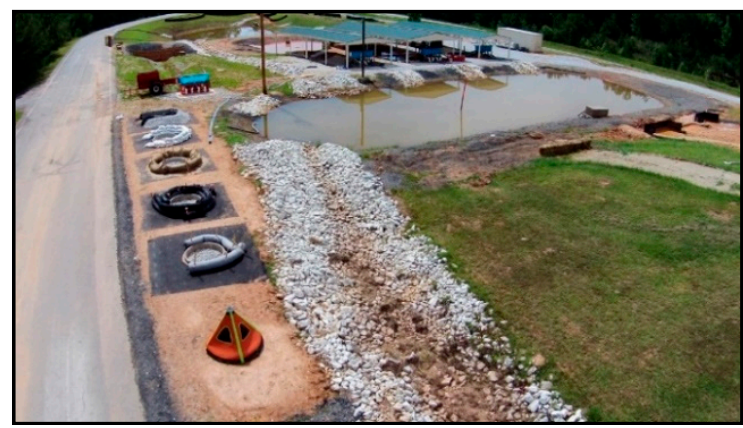

(b)

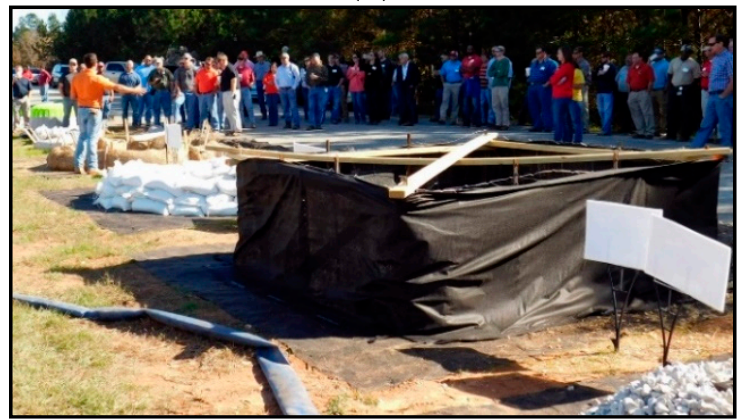

(d)

Figure 3. Inlet protection practices demonstration station: (a) development of demonstration area, (b) installed practices during field day, (c) participants during hand-on installer seminar, (d) demonstration during field day.

Station O: Pipe Inlet Protection. Pipe inlet protection practices are installed in a small section of pipe to showcase their applicability and function in reducing runoff velocity upstream of culverts. Product vendors are allowed to demonstrate their products near this station to aid in demonstrating each proprietary products purpose, function, and uniqueness.

Station P: Meeting and Break Area. A 12.2 by $22.9 \mathrm{~m} \mathrm{(40} \mathrm{by} 75 \mathrm{ft})$ tent is installed and outfitted with tables and chairs to provide seating and a gathering area for instruction, vendor setup and interaction, and breaks. The vendor setup areas allow for product manufacturers to showcase innovative products and provide course participants with marketing materials. 


\section{Training Events}

Innovative ESC Research Showcase and Field Day. The first technology transfer event hosted by the AU-ESCTF was a two-day seminar held in May 2014. This event introduced participants to the research being performed by various universities in the southeast, with emphasis on solving ESC problems in the construction sector. The training effort was divided into classroom and outdoor field instructional sessions. The classroom sessions (Figure 4a) included presentations on: (1) U.S. Environmental Protection Agency's perspective on environmental compliance, (2) environmental leadership, and (3) the latest findings from cutting-edge research being performed by Auburn University, North Carolina State University, and the University of Georgia, on effective ESC practice implementation. The field instructional session was held at the AU-ESCTF and provided attendees with a hands-on opportunity to: (1) learn proper installation techniques on various ESCs to achieve improved performance, (2) observe full-scale, channelized flow testing demonstrations, and (3) interact with vendors and manufacturers of current ESC products. Participants who completed this seminar received 1.20 continuing education units (CEUs).

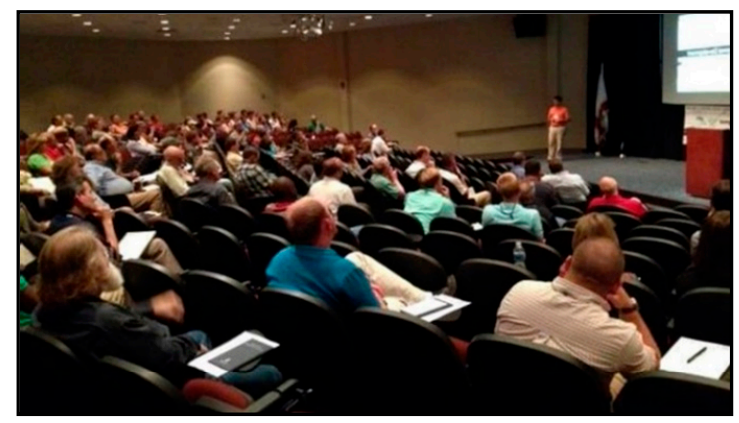

(a)

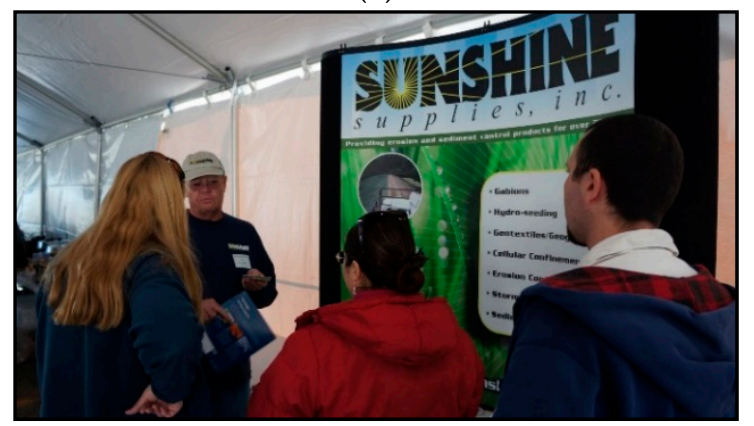

(c)

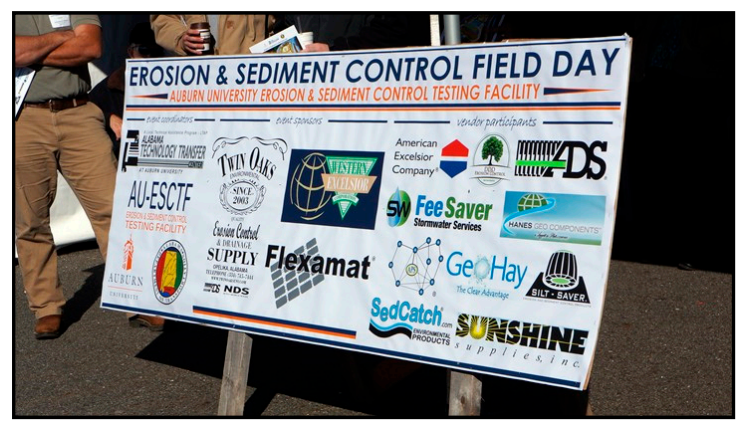

(b)

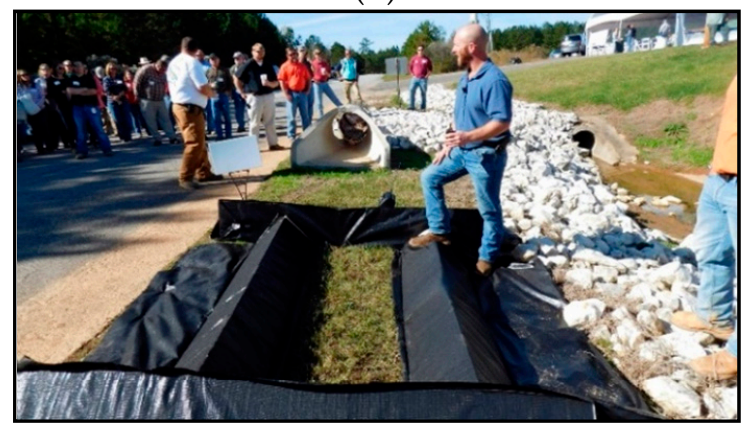

(d)

Figure 4. (a) seminar presentations; (b) sponsor recognition; (c) vendor interaction with participants, (d) vendor installed product demonstration.

This event was hosted in partnership with the IECA University Partners Program to facilitate their mission of providing regional training events. In addition, Thompson Engineering partnered with the event by providing QCI refresher course credit for attendees that participate in their QCI training program.

To engage participants with industry tools and to help offset costs associated with hosting the event, product vendors were invited to participate as sponsors in the training event. In return, vendors were recognized for their participation (Figure 4b); given a booth area to display product information (Figure 4c); and had the opportunity to install their product on select areas of the facility, allowing them to effectively market their devices to the course participants (Figure 4d).

Innovative ESC Field Day. On November 2014, a field day was hosted in collaboration with an ALDOT classroom-based training event for stormwater designers. The purpose of the field day was to reinforce design concepts learned by participants in the classroom component with demonstrations 
of ESC practice installations and overall performance. The primary goal of this field day was to provide exposure to designers with innovative research being performed on commonly employed erosion and sediment control practices with hands-on field demonstrations. The field instructional session provided attendees with a hands-on opportunity to: (1) learn proper installation techniques on various ESCs to achieve improved performance, and (2) observe full-scale, channelized flow testing demonstrations. As with the first event, vendors were invited to participate in the educational program. Participants attending this seminar received 0.60 CEUs.

ESC Hands-On Installer Training. One-and-a-half day training events were hosted on November 2015, November 2016 and March 2018. The focus of these events was on providing classroom and hands-on training geared for participants involved in the installation of construction site ESC practices. A half-day classroom component covered a wide variety of topics that were reinforced with field installations during the following, full-day field component. The field component required trainee participation to install ESC practices in a typical field setting and included channelized flow demonstrations to show the effectiveness of properly installed practices. The events were targeted at smaller groups of participants and involved a much higher and more active level of engagement. Participants gained knowledge learned from research experience in hands-on installation and implementation tools to provide efficient and effective ESCs. These installer trainings were followed by Innovative Erosion and Sediment Control Field Days, held on November 2015, November 2016, and March 2018 that were geared towards demonstrating various innovative ESC practices to a wider audience. Participants attending these seminars received 0.90 CEUs for the Installer Training and 0.60 CEUs for the Innovative Erosion and Sediment Control Field Days.

IECA Environmental Connection Field Day. In February 2017, a one-day research showcase and field day was held at the AU-ESCTF. The event was organized as a pre-conference activity during the 2017 Environmental Connection Conference (EC17) hosted by IECA in Atlanta, GA. The field event included a bus tour from the EC17 conference site to the AU-ESCTF. During the two-hour bus tour, researchers presented findings of the AU-ESCTF program. This gave participants an overview of the mission, purpose, and outcomes of the unique collaboration between ALDOT and Auburn University. Upon arrival at the facility, participants were given a tour of the facility, which included running flow simulations on active research and demonstration stations. This activity broadened the reach of training participants beyond the southeastern states, and for the first time, beyond the U.S. borders.

\section{Results and Discussion}

Participant Demographics. The ATAP advertises events through their website, emails, and mailers. In addition, the AU-ESCTF website provides advertisements and links to the ATAP registration pages. The target audience of these field days include:

- technical staff or end users within DOTs;

- local agencies looking to implement new technology that has been used on the state level;

- road builders, designers, land use planners, and engineers;

- county, city, and university MS4 officials, engineers, and environmental management consultants; and

- the environmental community and citizens interested in learning about ESC for construction sites.

Through the nine offered trainings, 764 registrants have participated. Of the participants, 571 individual attendees participated, of which $22 \%$ have attended multiple AU-ESCTF training events. Four or more AU-ESCTF training events have been attended by $3 \%$ of the participant pool. A summary of individual seminar demographics is presented in Table 1 . The majority of attendees $(51 \%)$ are ALDOT or other public (i.e., local, state, or federal) employees. 
Table 1. Registration demographics.

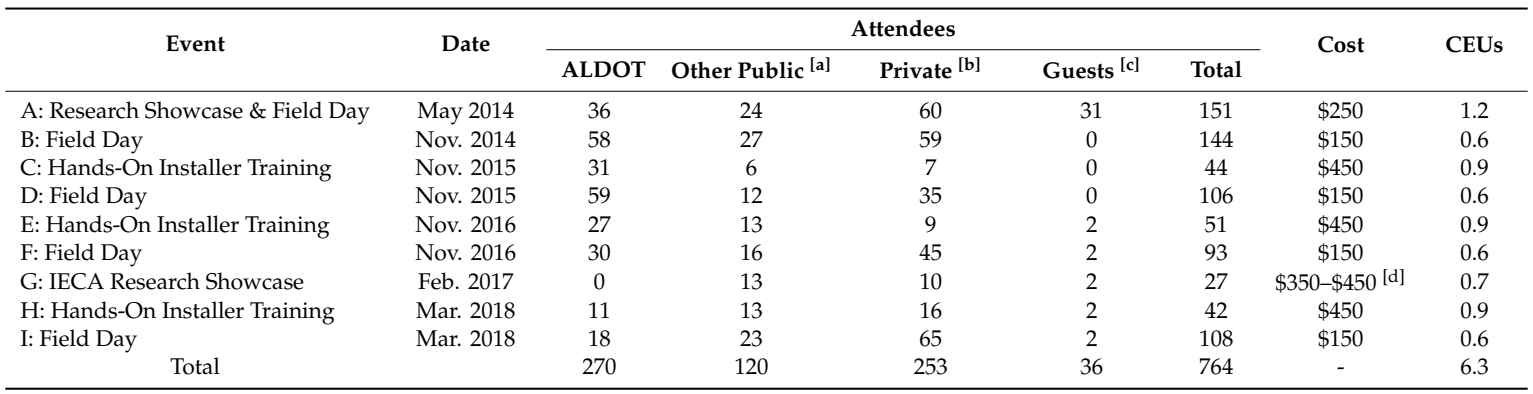

Notes: [a] includes federal agencies, state environmental agencies, local/municipality, university employees, etc. [b] includes private consultants, engineers, scientists, non-profit organizations, product manufactures, etc. [c] includes students and invited speakers (instructors not counted). [d] registration cost varied based on IECA membership status and date of registration.

Participants attending Hands-On Installer Training (2018) identified primarily as inspectors (27\%) and supervisors (25\%), with $17 \%$ identifying as installers. The top three categories for Field Day (2018) include: inspectors $(29 \%)$, supervisors $(27 \%)$, and regulators $(16 \%)$.

Figure 5 maps counties in which individual participants reside. This map represents all hosted events, and indicates that the largest density of participants came from the Alabama counties of Baldwin, Jefferson, Lee, Mobile, and Montgomery. Future efforts should be made to extend the reach of the training program to underserved areas of the state and Southeastern U.S. The data were obtained from registrants' addresses used during the event registration process. Note, vendors and guests are not included in Figure 5.

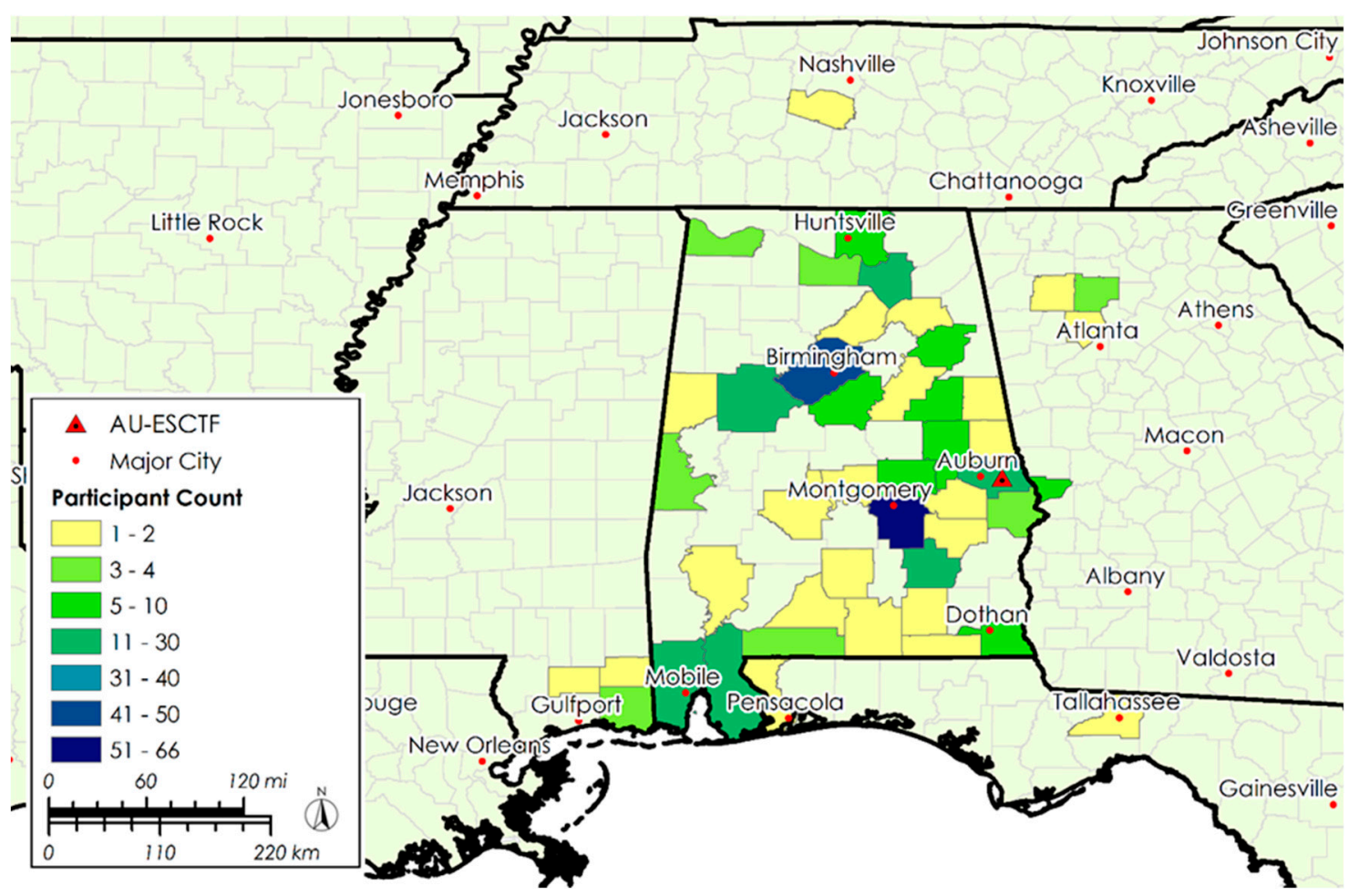

Figure 5. Distribution of participant registration addresses. Not mapped: Alaska (5), Massachusetts (1), Michigan (3), Nevada (2), North Carolina (2), South Carolina (1), Texas (1), Vermont (1), Japan (1), and Malaysia (1).

Of the surveys, $24 \%$ of respondents identified themselves as designers, $24 \%$ as inspectors, $16 \%$ as regulators, $16 \%$ as suppliers or product manufactures, $11 \%$ as supervisors, and $11 \%$ as other. 
To assess the quality of the seminars, surveys were distributed in paper format at the conclusion of each training event. Respondents are asked to provide a rating on a scale of 1 to 5 (with 5 being the highest) to a series of questions regarding individual components of the seminar including program content, instructor effectiveness, and course organization. A summary of the results are presented in Table 2.

Table 2. Summary of survey responses ${ }^{[a]}$ for individual events.

\begin{tabular}{|c|c|c|c|c|c|c|c|c|c|}
\hline Event $^{[b]}$ & A & $\mathrm{C}$ & D & $\mathbf{E}$ & $\mathbf{F}$ & G & $\mathbf{H}$ & I & Avg \\
\hline The program content was: & 4.6 & 4.3 & 4.4 & 4.3 & 4.4 & 4.7 & 4.5 & 4.3 & 4.4 \\
\hline The speaker's knowledge on the subject was: & 4.7 & 4.6 & 4.6 & 4.6 & 4.7 & 5.0 & 4.5 & 4.5 & 4.7 \\
\hline The speaker's effectiveness in teaching subject matter was: & 4.7 & 4.5 & 4.4 & 4.5 & 4.7 & 5.0 & - & - & 4.6 \\
\hline The program organization was: & 4.5 & 4.3 & 4.2 & 4.3 & 4.3 & 5.0 & 4.5 & 4.3 & 4.4 \\
\hline Interaction with Auburn University personnel was: & 4.6 & 4.5 & 4.4 & 4.5 & 4.6 & 4.9 & 4.5 & 4.4 & 4.6 \\
\hline The facility was: & 4.7 & 4.4 & 4.4 & 4.1 & 4.5 & 4.9 & 4.5 & 4.3 & 4.5 \\
\hline Average & 4.6 & 4.3 & 4.4 & 4.3 & 4.5 & 4.8 & 4.5 & 4.3 & 4.5 \\
\hline
\end{tabular}

Note: [a] each response was recorded on a scale of: Excellent (5), Very Good (4), Good (3), Fair (2), and Poor (1). [b] A: Research Showcase and Field Day, May 2014; B: Field Day, Nov. 2014 (surveys not recorded); C: Hands-On Installer Training, Nov. 2015; D: Field Day, Nov. 2015; E: Hands-On Installer Training, Nov. 2016; F: Field Day, Nov. 2016; G: IECA Environmental Connection Field Day, Feb. 2017; H: Hands-On Installer Training, Mar. 2018; I: Field Day, Mar. 2018.

To improve feedback received from participants, AU-ESCTF researchers began distributing online surveys with additional feedback following the 2016 training programs. The average response rate for the surveyed events was $22 \%$. The 2018 training events were surveyed using pre and post surveys handed out at the beginning and end of the course. This resulted in essentially $100 \%$ survey responses.

An indicator of training quality is the perceived change in knowledge by program participants. In distributed surveys, attendees were asked to rank their level of knowledge prior to and after attending the training programs in ten specific focus areas covered during training. The results for events $\mathrm{H}$ and I, organized in Figure 6a by individual topics, and summarized by overall change in knowledge in Figure 6b, indicate that the knowledge level was improved across all measured areas. The individual practices that had the greatest increase in knowledge gain were slope drains, slope interrupters, and flocculent, at average increases of $75 \%, 73 \%$, and $70 \%$, respectively. This significant increase in perceived knowledge was primarily due to the three practices ranking in the lowest levels of knowledge prior to attendees participating in the training events. The highest ranking in post-training knowledge was given to ditch checks, inlet protection practices, sediment barriers, and slope drains. On average, the Installer Training event $(\mathrm{H})$ had a greater gain in knowledge at $82 \% \pm 0.8 \%$ than did the Field Day (I) at $36 \% \pm 0.2 \%$. This difference may be attributed to the greater level of contact time, smaller course size, amount of detail, and classroom and hands-on approach of the Installer Training program. Field day responses may be skewed, due to the high number of repeat attendees that attended both the Installer Training and Field Day. Overall, participant knowledge increased from 2.0 (moderate) to 3.0 (high), as indicated by Figure 6b. The figure further shows how the distribution of perceived knowledge shifts from a normal distribution towards a right-modal skew. 


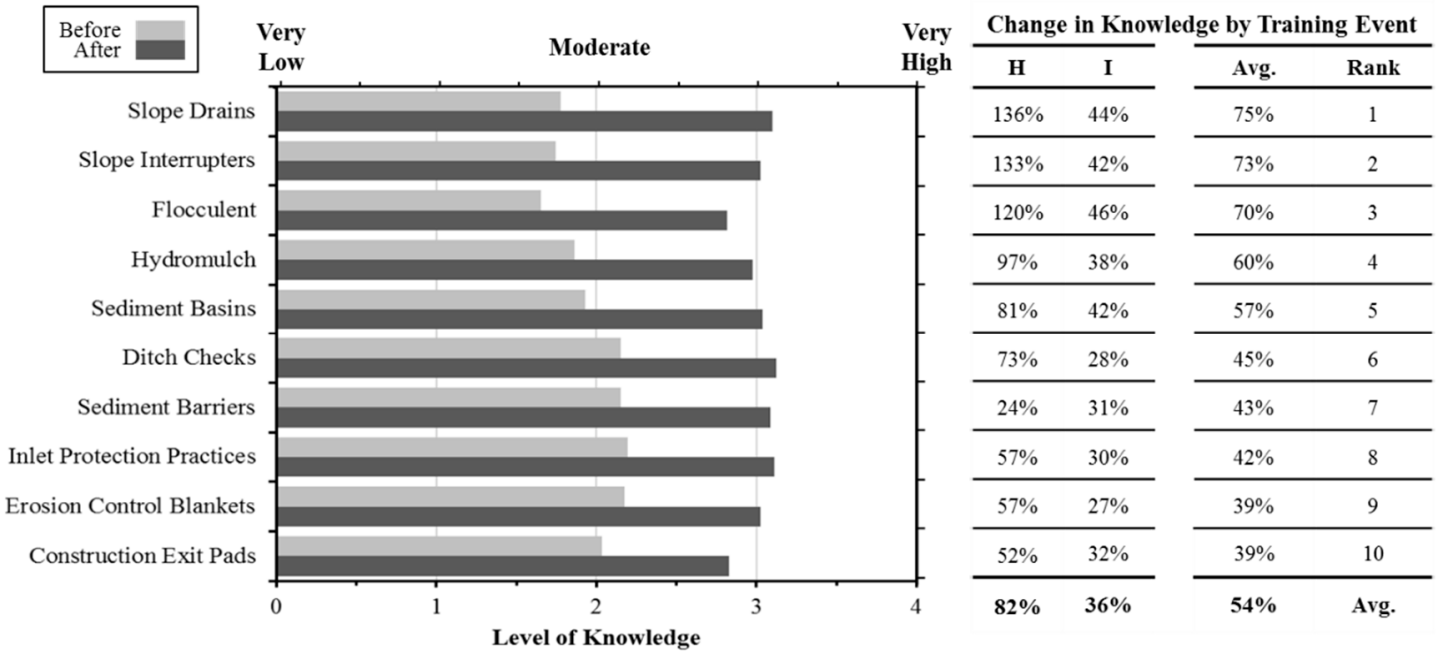

(a)

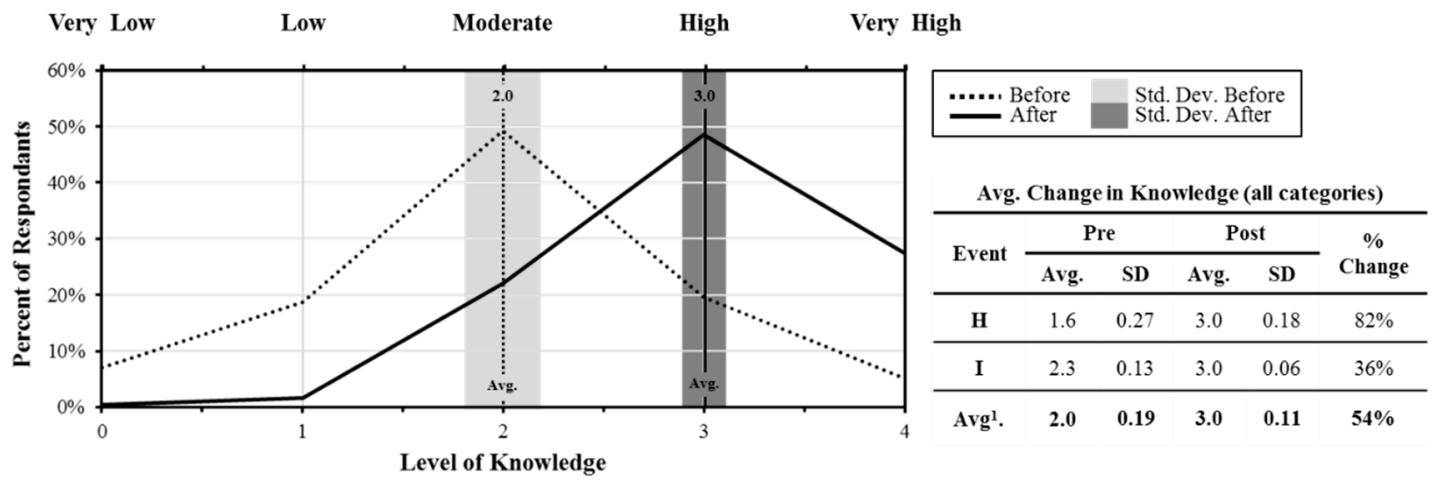

(b)

Figure 6. (a) Change in knowledge prior to and after attending AU-ESCTF training events, by category.

(b) Overall change in knowledge.

Survey respondents were additionally asked to leave personalized feedback on the seminar. The most common positive comments pertained to the hands-on components/field exercises, real-world and practical applicability of demonstrations, course organization, and student involvement. Constructive comments received included the need to include stream restoration components, and the desire for handouts or take-home materials. Examples of participant survey feedback are included below:

- "The program is well planned and well thought of."

- $\quad$ "I enjoyed the ability to see the best management practices in action and learn how they work in their environment."

- "I thought all the different stations, methods and products were very good. Visual learning was great."

\section{ALDOT Perspective}

With the need for environmental stewardship becoming of upmost importance, DOT agencies across the country are embracing initiatives to promote and strengthen their environmental ethical responsibilities [23]. ALDOT's environmental vision is for environmental responsibility to be an integrated culture of environmental consideration, stewardship, and advancement, which cultivates trust, enhancement, preservation, and compliance. ALDOT has decided that it must go beyond mere regulatory compliance in order to realize this vision. The primary components of the mission of the AU-ESCTF (research and development; product evaluation; and training) are helping ALDOT's vision to become reality in the area of construction stormwater management. 
State transportation agencies that have embraced "environmental stewardship" have recognized the importance of the stakeholder community, which can help dictate whether public opinion and media review of a project are favorable and whether transportation objectives can be achieved [23]. The work at AU-ESCTF is helping ALDOT achieve its regulatory requirements, and it is also evidence of action toward ALDOT's environmental goal and mantra of "Getting Better Every Day". Work at the facility has improved ALDOT design, construction, and maintenance practices; it has informed and improved ALDOT's standard drawings and specifications; and it has provided a forum where practitioners can see, first-hand, how water and practices likely behave in a real-world setting. Perhaps one of the most valuable outcomes of the research is a renewed realization and demonstration that challenging tradition and "rules of thumb" can lead to more effective and economical means of protecting Alabama waters.

An example of ALDOT implementation of AU-ESCTF research results is in the use of silt fence ditch checks with weirs along active construction sites. Figure 7a,b depict the installed practices along an active ALDOT construction project in Centreville, Alabama [24].

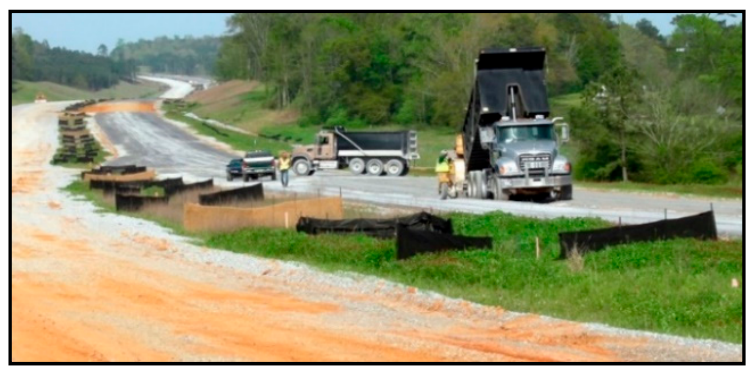

(a)

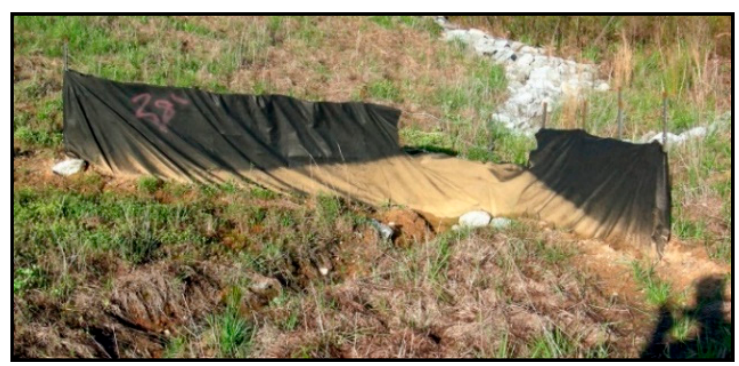

(b)

Figure 7. (a) In-field installation of silt fence ditch checks with weirs, (b) single silt fence ditch check with weir installed in field.

\section{Conclusions}

The AU-ESCTF serves as a center for research, product evaluation, and training. Over the last several years, the facility has hosted nine successful training events used to disseminate research results to industry practitioners in an effort to close the gap between research and implementation. Recent survey data indicate an increase in perceived knowledge gained by participants averaging $54 \%$.

Opportunities exist to improve the training activities, including providing take-home materials that provide key highlights (i.e., proper installation procedures, diagrams, and photographs). Further survey evaluation questions can be adapted to include elements of a researched evaluation model to measure the participants' level of satisfaction, learning, impact, adoption of technology, results, and return on investment [25].

With each field day, course development, site preparation, and setup have become less resource and time consuming; however, the events still disrupt regular research activities as has been noted by other laboratories that perform technology transfer activities [26]. In addition, the field days carry a high cost in acquiring demonstration materials, portable facilities, and meals/refreshments. When possible, materials were obtained through vendor donations to help offset the costs. Hosting a hands-on installer training the day prior to a field-day decreases the time and resources required to fully setup demonstration stations, as the course participants assist in the installation of the ESC practices. While the planned outdoor events have fortunately not been adversely disrupted by weather conditions, the nature of the activities leaves it highly vulnerable.

Due to continued interest and positive feedback received by attendees, Hands-On Installer Training and Field Day events will be offered regularly at the AU-ESCTF. The potential for an installer-based certification program can emanate from these training efforts, as industry leaders see the advantage in 
providing a hands-on approach to disseminating effective ESC practices to those who are in the field installing the devices.

Author Contributions: Conceptualization, M.A.P., W.C.Z., and W.N.D.; methodology, M.A.P., W.C.Z., validation, M.A.P., W.C.Z., formal analysis, M.A.P., W.C.Z., investigation, M.A.P., resources, W.C.Z., R.T., B.G.F.; data curation, M.A.P., writing — original draft preparation, M.A.P., W.N.D., B.G.F.; writing—review and editing, W.C.Z., R.T.; visualization, M.A.P., supervision, W.C.Z., project administration, W.C.Z., R.T.

Funding: This research received no external funding.

Acknowledgments: The authors would like to acknowledge the AU-ESCTF research technicians and undergraduate assistants, as well as NCAT staff, and the ATAP for their assistance in hosting these successful training events. These events would not be possible without the continued research sponsorship by ALDOT; the authors gratefully acknowledge this financial support. The findings, opinions, and conclusions expressed in this paper are those of the authors and do not necessarily reflect the view of the sponsor.

Conflicts of Interest: The authors declare no conflict of interest.

\section{References}

1. Duan, W.; Takara, K.; He, B.; Luo, P.; Nover, D.; Yamashiki, Y. Spatial and temporal trends in estimates of nutrient and suspended sediment loads in the Ishikari River, Japan, 1985 to 2010. Sci. Total Environ. 2013, 461-462, 499-508. [CrossRef] [PubMed]

2. Duan, W.L.; He, B.; Takara, K.; Luo, P.P.; Nover, D.; Hu, M.C. Modeling suspended sediment sources and transport in the Ishikari River basin, Japan, using SPARROW. Hydrol. Earth Syst. Sci. 2015, 19, 1293-1306. [CrossRef]

3. Kerr, S.J. Silt, Turbidity and Suspended Sediments in the Aquatic Environment: An Annotated Bibliography and Literature Review; Ontario Ministry of Natural Resources, Southern Region Science and Technology Transfer Unit: North Bay, ON, Canada, 1995.

4. Helms, D. The Civilian Conservation Corps: Demonstrating the Value of Soil Conservation. J. Soil Water Consercation 1985, 40, 184-188.

5. United States Environmental Protection Agency. National Pollutant Discharge Elimination System (NPDES) Permit Writers' Manual; United States Environmental Protection Agency: Washington, DC, USA, 2010.

6. United States Environmental Protection Agency. Construction General Permit (CGP)_Fact Sheet; United States Environmental Protection Agency: Washington, DC, USA, 2012.

7. Alabama Soil and Water Conservation Committee. Alabama Handbook for Erosion Control, Sediment Control and Stormwater Management on Construction Sites and Urban Areas; Alabama Soil and Water Conservation Committee: Montgomery, AL, USA, 2018.

8. Whitman, J.B.; Zech, W.C.; Donald, W.N. Full-Scale Performance Evaluations of Innovative and Manufactured Sediment Barrier Practices. Transp. Res. Rec. 2019, 2673. [CrossRef]

9. Bugg, R.; Donald, W.; Zech, W.; Perez, M. Performance Evaluations of Three Silt Fence Practices Using a Full-Scale Testing Apparatus. Water 2017, 9, 502. [CrossRef]

10. Perez, M.A.; Zech, W.C.; Donald, W.N.; Fang, X. Methodology for Evaluating Inlet Protection Practices Using Large-Scale Testing Techniques. ASCE J. Hydrol. Eng. 2014, 20. [CrossRef]

11. Perez, M.A.; Zech, W.C.; Fang, X.; Vasconcelos, J.G. Methodology and Development of a Large-Scale Sediment Basin for Performance Testing. ASCE J. Hydrol. Eng. 2016, 142. [CrossRef]

12. Perez, A.M.; Zech, C.W.; Vasconcelos, G.J.; Fang, X. Large-Scale Performance Testing of Temporary Sediment Basin Treatments and High-Rate Lamella Settlers. Water 2019, 11, 316. [CrossRef]

13. Perez, M.A.; Zech, W.C.; Donald, W.N.; Fang, X. Installation Enhancements to Common Inlet Protection Practices (IPPs) using Large-Scale Testing Techniques. Transp. Res. Rec. J. Transp. Res. Board 2016, 2521, 151-161. [CrossRef]

14. Perez, M.A.; Zech, W.C.; Donald, W.N.; Fang, X. Design Methodology for the Selection of Temporary Erosion and Sediment Control Practices Based on Regional Hydrological Conditions. ASCE J. Hydrol. Eng. 2016, 21. [CrossRef]

15. Sherwood, D.A. Effects of a Vegetated Stormwater-Detention Basin on Chemical Quality and Temperature of Runoff from a Small Residential Development in Monroe County, New York; U.S. Geological Survey: Reston, VA, USA, 2001. 
16. Hood, M.M.; Thompson, S.R.; Vance, R.J.; Renz, M.S.; Harder, B.T.; Toole, J.; Hunter, S.T. NCHRP Report 768: Guide to Accelerating New Technology Adoption through Directed Technology Transfer; Transportation Research Board: Washington, DC, USA, 2014.

17. Pitt, R.; Clark, S.E.; Lake, D.W. Construction Site Erosion and Sediment Controls; DEStech Publications Inc.: Lancaster, PA, USA, 2007.

18. Gomillion, C.G.; Norrell, R.J. Alabama. Encycl. Br. 2019.

19. Harder, B.T. NCHRP Synthesis 461: Accelerating Implementation of Transportation Research Results; Transportation Research Board of the National Academies: Washington, DC, USA, 2014.

20. Donald, W.N.; Zech, W.C.; Fang, X.; LaMondia, J.J. Evaluation of Wheat Straw Wattles for Velocity Reduction in Ditch Check Installations. Transp. Res. Rec. J. Transp. Res. Board 2013, 2358, 69-78. [CrossRef]

21. Donald, W.N.; Zech, W.C.; Fang, X.; Asce, F. Comparative Evaluation of Wattle Ditch Checks Composed of Differing Materials and Properties. ASCE J. Irrig. Drain. Eng. 2015, 141, 1-9. [CrossRef]

22. Donald, W.N.; Zech, W.C.; Fang, X.; Perez, M.A. Hydraulic Method to Evaluate the Performance of Ditch Check Practices and Products. ASCE J. Hydrol. Eng. 2016, 21, 04016042. [CrossRef]

23. Venner, M. Measuring Environmental Performance at State Transportation Agencies. Transp. Res. Rec. J. Transp. Res. Board 2003, 1859, 9-18. [CrossRef]

24. Donald, W.N.; Zech, W.C.; Perez, M.A.; Fang, X. Evaluation and Modification of Wire-Backed Nonwoven Geotextile Silt Fence for Use as a Ditch Check. ASCE J. Irrig. Drain. Eng. 2015, 142. [CrossRef]

25. Naugle, K.A.; Naugle, L.B.; Naugle, R.J. Kirkpatrick's Evaluation Model as a Means of Evaluating Teacher Performance. Education 2000, 121, 135-145.

26. Coursey, D.; Bozeman, B. Technology Transfer in U.S. Government and University Laboratories: Advantages and Disadvantages for Participating Laboratories. IEEE Trans. Eng. Manag. 1992, 90, 347-351. [CrossRef]

(C) 2019 by the authors. Licensee MDPI, Basel, Switzerland. This article is an open access article distributed under the terms and conditions of the Creative Commons Attribution (CC BY) license (http://creativecommons.org/licenses/by/4.0/). 